\title{
STABILITY INDICATIVE AND COST EFFECTIVE ANALYTICAL METHOD DEVELOPMENT AND VALIDATION OF FENOFIBRIC ACID AND PITAVASTATIN BY USING RP-HPLC
}

\section{RAMCHANDRAN ${ }^{*}$, ANITHA KETHIPALLI ${ }^{b}$, MANNAM KRISHNAMURTHYc}

${ }^{*}$,bDepartment of Chemistry, Acharya Nagarjuna University, Guntur, AP 522510, India, cANU Research Center, SVRM College, Nagaram, AP, India

*Email: ramchandran.anu22@gmail.com

Received: 18 May 2021, Revised and Accepted: 06 Jul 2021

\section{ABSTRACT}

Objective: The current investigation was pointed at developing and progressively validating novel, simple, responsive and stable RP-HPLC method for the measurement of active pharmaceutical ingredients of Fenofibric acid and Pitavastatin.

Methods: A simple, selective, validated and well-defined stability that shows gradient RP-HPLC methodology for the quantitative determination of Fenofibric acid and Pitavastatin. The chromatographic strategy utilized X-bridge phenyl column of dimensions $250 \times 4.6 \mathrm{~mm}, 5 \mathrm{micron}$, using isocratic elution with a mobile phase of acetonitrile and 0.1 percent formic acid (60:40). A flow rate of $1 \mathrm{ml} / \mathrm{min}$ and a detector wavelength of 242 $\mathrm{nm}$ utilizing the PDA detector were given in the instrumental settings. Validation of the proposed method was carried out according to an international conference on harmonization (ICH) guidelines.

Results: LOD and LOQ for the two active ingredients were established with respect to test concentration. The calibration charts plotted were linear with a regression coefficient of $\mathrm{R}^{2}>0.999$, means the linearity was within the limit. Recovery, specificity, linearity, accuracy, robustness, ruggedness were determined as a part of method validation and the results were found to be within the acceptable range.

Conclusion: The proposed method to be fast, simple, feasible and affordable in assay condition. During stability tests, it can be used for routine analysis of the selected drugs.

Keywords: Fenofibric acid, Pitavastatin, RP-HPLC, Development, Validation

(c) 2021 The Authors. Published by Innovare Academic Sciences Pvt Ltd. This is an open access article under the CC BY license (https://creativecommons.org/licenses/by/4.0/) DOI: https://dx.doi.org/10.22159/ijap.2021v13i5.42097. Journal homepage: https://innovareacademics.in/journals/index.php/ijap

\section{INTRODUCTION}

The active form of fenofibrate, a synthetic phenoxy-isobutyric acid derivate having antihyperlipidemic [1] action, is fenofibric acid. Fenofibric acid is a lipid-lowering [2] drug used to treat severe hypertriglyceridemia [3, 4], primary hyperlipidemia, and mixed dyslipidemia. It operates by lowering high-density lipoprotein [5, 6] cholesterol, total cholesterol, triglycerides [7], and apolipoprotein B $[8,9]$ while raising low-density lipoprotein cholesterol. The prodrug, [fenofibrate], and other conjugated derivatives of fenofibric acid, such as choline fenofibrate, have been created for enhanced solubility, gastrointestinal [10] absorption, and bioavailability [11], as well as more convenient administration due to its high hydrophilicity and poor absorption profile.

Pitavastatin (usually as a calcium salt) is a member of the blood cholesterol [12] lowering medication class of statins [13, 14]. It inhibits HMG-CoA reductase [15], the enzyme that catalyses the first step in cholesterol production, like other statins. Pitavastatin, like the other statins, is used to treat hypercholesterolemia [16, 17] (high cholesterol) and to prevent cardiovascular disease [18, 19]. The side effects of common statins (headaches, stomach upset, abnormal liver function tests, and muscle cramps [20]) were similar to those of other statins. Pitavastatin, on the other hand, appears to cause fewer muscular adverse effects than some lipidsoluble statins, owing to its water-soluble nature (as is pravastatin, for example). Coenzyme Q10 [21] was not lowered as much as other statins (albeit this is unexpected given the underlying chemistry of the HMG-CoA reductase pathway, which all statin medicines inhibit) [22,23]. Pitavastatin, in contrast to other statins, has been shown to ameliorate insulin resistance [24] in humans, as measured by the homeostatic model assessment (HOMA-IR) method [25]. Pitavastatin has been linked to hyperuricemia [26] and higher levels of blood uric acid [27]. The aim of the study is to separate the pharma ingredients Fenofibric and Pitavastatin by using RP-HPLC.

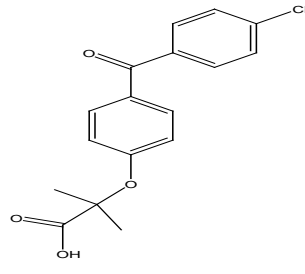

A

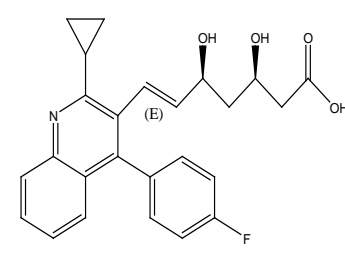

B
Fig. 1: Structure of (A) Fenofibric acid and (B) Pitavastatin

\section{MATERIALS AND METHODS}

\section{Chemicals}

Acetonitrile, HPLC-grade formic acid, water were purchased from Merck India Ltd, Mumbai, India. APIs of Fenofibric acid, Pitavastatin standards were procured from Glenmark, Mumbai.

\section{The Instrumentation}

Waters alliance liquid chromatography (model 2695) was monitored with empower 2.0 data handling system and a detector of photodiode array (model 2998) was used for this study.

\section{Method optimization}

To optimize the chromatographic conditions, different ratios of phosphate buffer and the acetonitrile in the mobile phase with isocratic and gradient mode was tested. However, the mobile phase composition was modified at each trial to enhance the resolution and also to achieve acceptable retention times. Finally, $0.1 \%$ formic acid buffer and acetonitrile with isocratic elution was selected because it results in a greater response of active pharmacy ingredients. During the optimization of the method various stationary phases such as $\mathrm{C}_{8}, \mathrm{C}_{18}$ and amino, phenyl columns were 
tested. From these trials the peak shapes were relatively good with X-bridge phenyl column of $250 \times 4.6 \mathrm{~mm}, 5 \mu$ with a PDA detector. The mobile phase flow rate has been done at $242 \mathrm{~nm}$ in order to obtain enough sensitivity. By using the above conditions, we get retention times of Fenofibric acid and Pitavastatin were about 2.7 min and 7.3 min with a tailing factor of 1.02 and 1.34 . The number of theoretical plates for Fenofibric acid and Pitavastatin were 5216, 7421 , which indicate the column's successful output the \% RSD for six replicate injections was around $0.08 \%$ and $0.16 \%$, the proposed approach suggests that it is extremely precise. According to ICH guidelines, the method established was validated.

Till today there are no HPLC methods were reported in the literature, but only few methods are developed in individual analysis of Fenofibric acid and Pitavastatin. Hence we developed method for the simultaneous quantification of Fenofibric acid and Pitavastatin. The developed HPLC method was utilized for the estimation of the combined drugs by in vitro method. Different extractions were tried using acetonitrile, methanol, and dimethylformamide.

\section{Validation procedure}

The analytical parameters such as system suitability, precision, specificity, accuracy, linearity, robustness, LOD, LOQ, forced degradation and stability were validated according to ICH Q2 (R1) guidelines [28, 29].

\section{Preparation of buffer}

$1 \mathrm{ml}$ of formic acid is dissolved in 1 lt of HPLC grade water and filter through $0.45 \mu$ filter paper.

\section{Chromatographic conditions}

The HPLC analysis was performed on a reverse-phase HPLC system with isocratic elution mode using a mobile phase of acetonitrile and $0.1 \%$ formic acid and X-bridge phenyl $(250 \times 4.6 \mathrm{~mm}, 5 \mu)$ column with a flow rate of $1 \mathrm{ml} / \mathrm{min}$.

\section{Diluent}

Mobile phase was used as a diluent.

\section{Preparation of the standard stock solution}

For standard stock solution preparation, add $70 \mathrm{ml}$ of diluents to $175 \mathrm{mg}$ of Fenofibric acid and $10 \mathrm{mg}$ of Pitavastatin taken in a 100 $\mathrm{ml}$ volumetric flask and sonicate for $10 \mathrm{~min}$ to fully dissolve the contents and then makeup to the mark with diluent.

\section{Preparation of Standard solution}

$1 \mathrm{ml}$ of solution is drawn from the above normal stock solution into a $10 \mathrm{ml}$ volumetric flask and diluted up to the level.

\section{RESULTS AND DISCUSSION}

The main analytical challenge during the development of a new method was to separate active Pharma ingredients. In order to provide a good performance, the chromatographic conditions were optimized.

\section{System suitability}

In System, suitability injecting standard solution and reported USP tailing and plate count values are tabulated in table 1 .

Table 1: Results of system suitability

\begin{tabular}{llll}
\hline System suitability parameter & Acceptance criteria & Drug name \\
\cline { 2 - 4 } & & Fenofibric acid & Pitavastatin \\
\hline USP Plate Count & NLT 2000 & 5216 & 7421 \\
USP Tailing & NMT 2.0 & 1.02 & 1.34 \\
USP Resolution & NLT 2.0 & - & 20.43 \\
$\%$ RSD & NMT 2.0 & 0.08 & 0.16 \\
\hline
\end{tabular}

\section{Specificity}

In this test method placebo, standard and standard solutions were analyzed individually to examine the interference. The below fig. shows that the active ingredients were well separated from blank and their excipients and there was no interference of placebo with the principal peak. Hence the method is specific.

\section{Linearity}

The area of the linearity peak versus different concentrations has been evaluated for Fenofibric acid, Pitavastatin, as 10, 25, 50, 100, 125,150 percent, respectively. Linearity was performed in the range of $17.5-262.5 \mu \mathrm{g} / \mathrm{ml}$ of Fenofibric acid and $1-15 \mu \mathrm{g} / \mathrm{ml}$ of Pitavastatin. The correlation coefficients achieved greater than 0.999 for all.

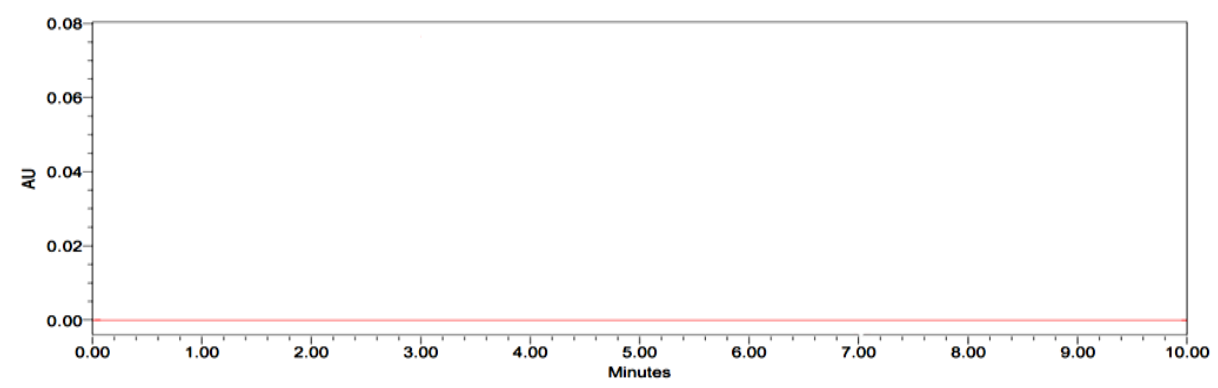

Fig. 3: Chromatogram of blank

Table 2: Linearity of fenofibric acid and pitavastatin

\begin{tabular}{|c|c|c|c|c|}
\hline S. No. & Conc $\mu \mathrm{g} / \mathrm{ml}$ & Fenofibric acid area count & Conc. $\mu \mathrm{g} / \mathrm{ml}$ & Pitavastatin area count \\
\hline 1 & 17.50 & 336520 & 1.00 & 57846 \\
\hline 2 & 43.75 & 886321 & 2.50 & 174632 \\
\hline 3 & 87.50 & 1702453 & 5.00 & 295684 \\
\hline 4 & 175.00 & 3265942 & 10.00 & 563245 \\
\hline 5 & 218.75 & 4056897 & 12.50 & 722013 \\
\hline 6 & 262.50 & 4832016 & 15.00 & 859564 \\
\hline Correl coef & & 0.99982 & & 0.99933 \\
\hline Slope & & 18347.61 & & 56618.31 \\
\hline intercept & & 44332.33 & & 9791.70 \\
\hline
\end{tabular}




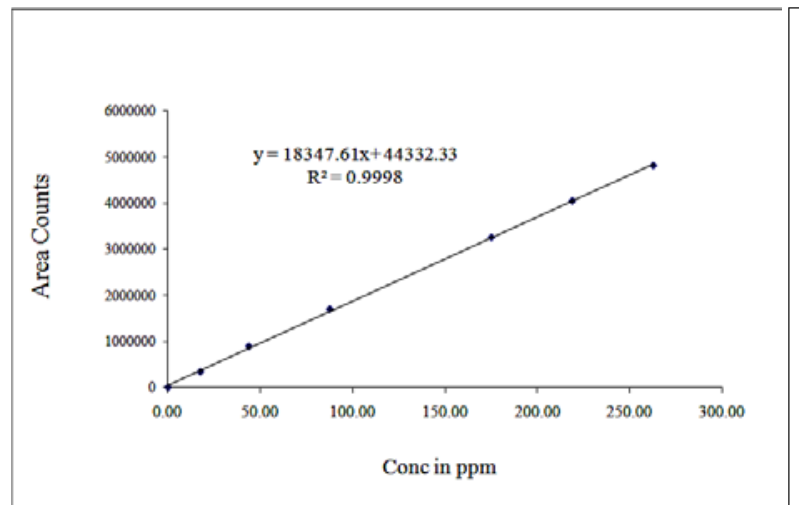

Fenofibric acid

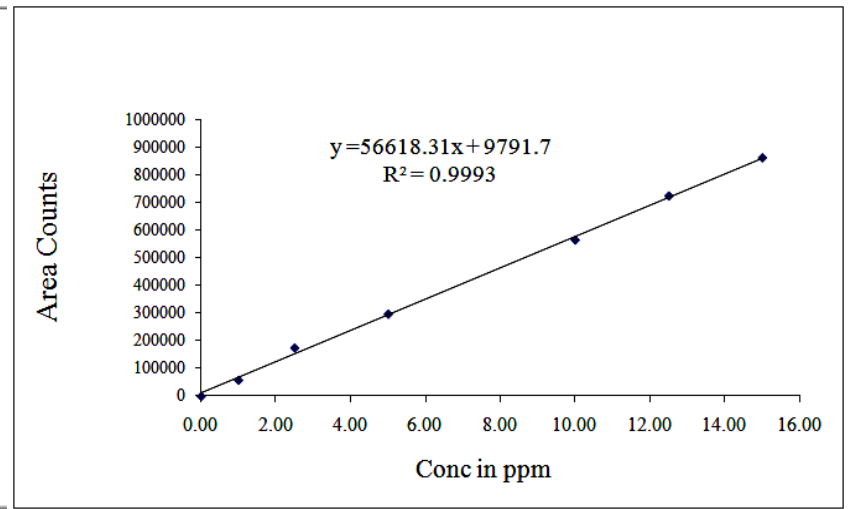

Pitavastatin

Fig. 4: Calibration plots of (A) Fenofibric acid (B) Pitavastatin

\section{Accuracy}

In this method, Accuracy was conducted in triplicate by analyzing active pharma ingredient standard solution at three kinds of concentration levels of 50,100 and $150 \%$ of each at a specified limit.
For all impurities, percentage recoveries were measured and found to be within the limit. The accuracy and reliability of the developed method were established. The percentage recovery values were found to be in the range of $99.97-100.66 \%$ for Fenofibric acid and 99.73-99.94\% for Pitavastatin. The results are given in table 3 .

Table 3: Results of accuracy

\begin{tabular}{llll}
\hline S. No. & \% Level & Fenofibric acid \% recovery & Pitavastatin \% recovery \\
\hline 1 & 50 & 99.97 & 99.73 \\
2 & 100 & 100.54 & 99.94 \\
3 & 150 & 100.66 & 99.88 \\
mean & & 100.39 & 99.85 \\
SD & & 0.369 & 0.108 \\
\hline
\end{tabular}

Mean+SD (n=3)

\section{Precision}

In method precision study, prepare six different standard solutions in the concentration of Fenofibric acid (175 ppm) and Pitavastatin (10 ppm) are injected into HPLC system. Fenofibric acid \%assay found to be in the range of 99.74-100.63 and Pitavastatin \%assay found to be in the range of 9948-100.85. These results are given below table 4 .

\section{Intraday precision}

Six replicates of a standard solution containing Fenofibric acid $(175 \mu \mathrm{g} / \mathrm{ml})$ and Pitavastatin $(10 \mu \mathrm{g} / \mathrm{ml})$ were analysed on the same day. Peak areas were calculated, which were used to calculate mean, SD and \%RSD values.

\section{Intermediate precision}

Six replicates of the standard solution were studied by various researchers, and on separate days different instruments were tested. The peak regions used to determine to mean percent RSD values have been calculated. The results are given in the following table.

\section{Inter-day precision}

Six replicates of a standard solution containing Fenofibric acid $(175 \mu \mathrm{g} / \mathrm{ml})$ and Pitavastatin $(10 \mu \mathrm{g} / \mathrm{ml})$ were analysed on a different day. Peak areas were calculated, which were used to calculate mean, $\mathrm{SD}$ and \%RSD values. The present method was found to be precise as the RSD values were less than $2 \%$ and also the percentage assay values were close to be $100 \%$. The results are given in table 5 .

Table 4: Intraday precision results of fenofibric acid and pitavastatin

\begin{tabular}{|c|c|c|c|c|c|c|}
\hline \multicolumn{4}{|c|}{ Fenofibric acid } & \multicolumn{3}{|l|}{ Pitavastatin } \\
\hline S. No. & Conc. $(\mu \mathrm{g} / \mathrm{ml})$ & Area counts & $\%$ assay as is & Conc. $(\mu \mathrm{g} / \mathrm{ml})$ & Area counts & \% Assay as is \\
\hline 1 & & 3265021 & 100.49 & & 567482 & 100.12 \\
\hline 2 & 175 & 3245786 & 101.05 & 10 & 563201 & 99.48 \\
\hline 3 & & 3285647 & 100.63 & & 564178 & 100.85 \\
\hline 4 & & 3263023 & 100.24 & & 563296 & 100.16 \\
\hline 5 & & 3248798 & 99.74 & & 562388 & 100.45 \\
\hline 6 & & 3247859 & 99.96 & & 564527 & 100.28 \\
\hline$\%$ RSD & 0.468 & \multirow{2}{*}{\multicolumn{2}{|c|}{100.35}} & 0.317 & & \\
\hline mean & & & & 100.3575 & & \\
\hline SD & & \multicolumn{2}{|c|}{0.474} & 0.119252 & & \\
\hline
\end{tabular}

Mean+SD (n=6) 


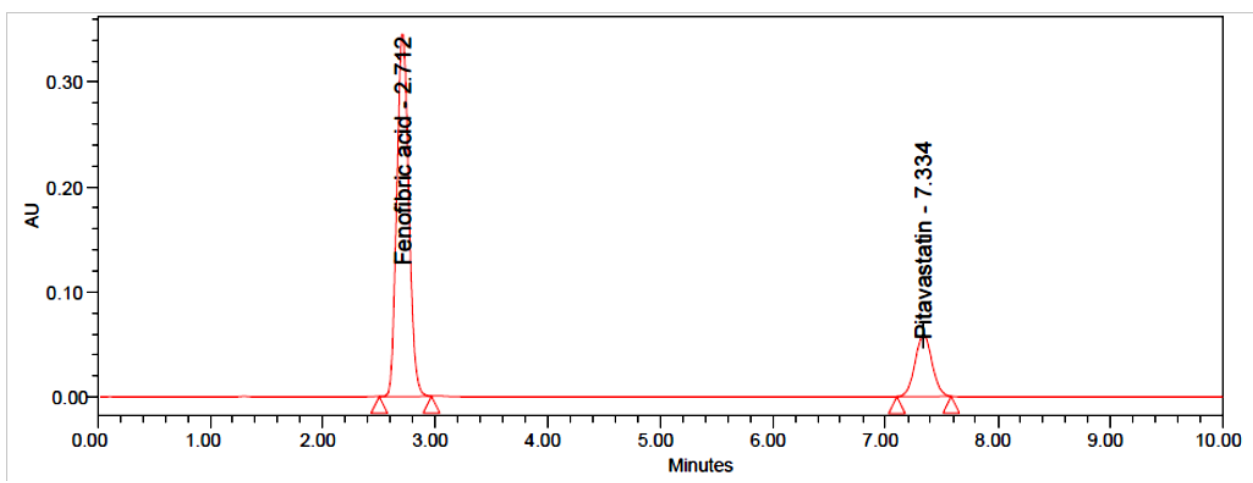

Fig. 5: Chromatogram of method precision

Table 5: Inter-day outcomes of the accuracy of fenofibric acid and pitavastatin

\begin{tabular}{lllllll}
\hline \multicolumn{2}{l}{ Fenofibric acid } & & & Pitavastatin & \\
\hline S. No. & Conc. $(\boldsymbol{\mu g} / \mathbf{m l})$ & Area counts & \% Assay as is & Conc. $(\boldsymbol{\mu g} / \mathbf{m l})$ & Area count & \% Assay as is \\
\hline 1 & & 3263635 & 100.54 & 10 & 569386 & 100.44 \\
2 & 175 & 3245187 & 100.27 & & 568245 & 98.63 \\
3 & & 3249587 & 100.63 & & 563214 & 99.04 \\
4 & 3206315 & 101.15 & & 567421 & 98.75 \\
5 & 3285632 & 100.39 & & 568239 & 99.64 \\
6 & & 9276942 & & 0.406 & 565210 & 99.68 \\
\%RSD & 0.868 & & & & \\
Mean & 100.44 & & & 0.686 & & \\
SD & 0.481 & & & & & \\
\hline
\end{tabular}

Mean+SD $(n=6)$

Table 6: LOD and LOQ for fenofibric acid and pitavastatin

\begin{tabular}{|c|c|c|c|c|c|c|c|}
\hline \multicolumn{4}{|l|}{ Fenofibric acid } & \multicolumn{4}{|l|}{ Pitavastatin } \\
\hline LOD & & LOQ & & LOD & & LOQ & \\
\hline Concentration & $\mathrm{s} / \mathrm{n}$ & Concentration & $\mathrm{s} / \mathrm{n}$ & concentration & $\mathrm{s} / \mathrm{n}$ & Concentration & $\mathrm{s} / \mathrm{n}$ \\
\hline $0.219 \mu \mathrm{g} / \mathrm{ml}$ & 7 & $0.722 \mu \mathrm{g} / \mathrm{ml}$ & 28 & $0.013 \mu \mathrm{g} / \mathrm{ml}$ & 3 & $0.041 \mu \mathrm{g} / \mathrm{ml}$ & 23 \\
\hline
\end{tabular}

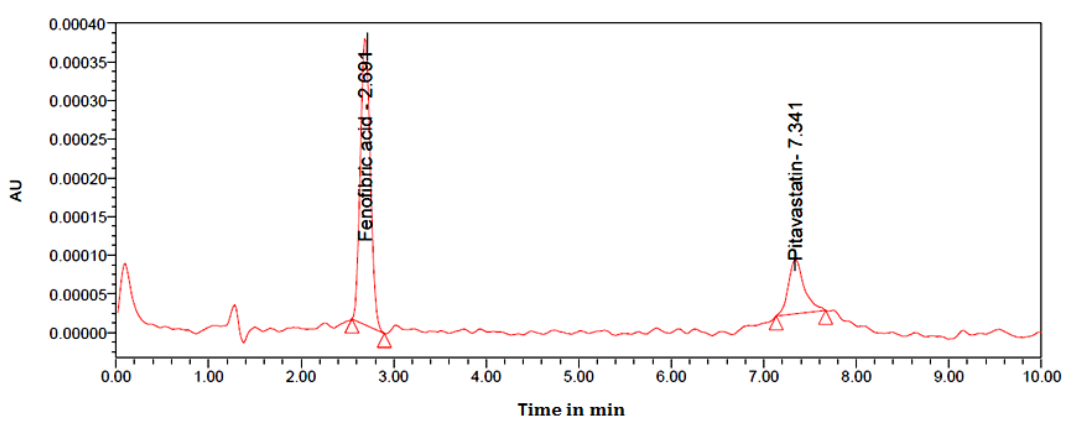

A

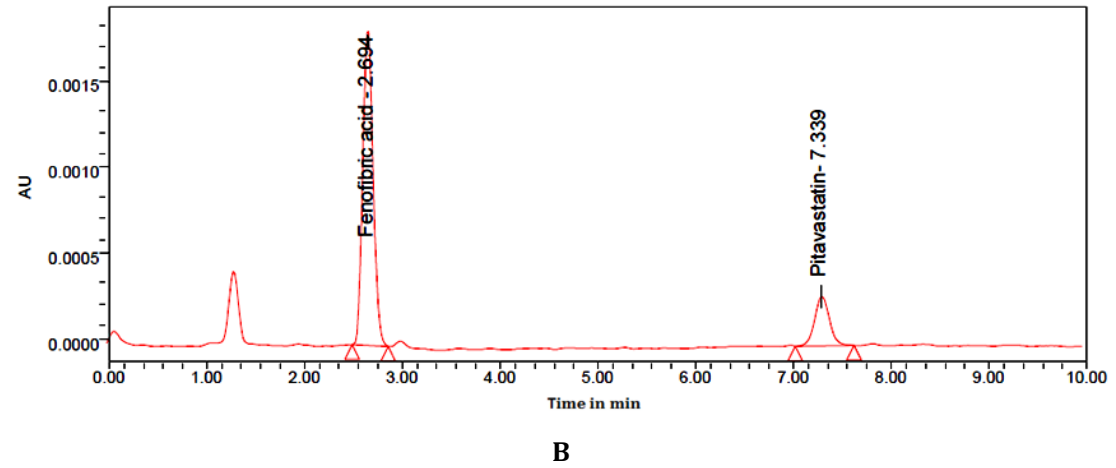

Fig. 6: Chromatogram of (A) LOD and (B) LOQ 


\section{LOD and LOQ}

The LOD concentrations for Fenofibric acid are $0.219 \mu \mathrm{g} / \mathrm{ml}$ and $\mathrm{s} / \mathrm{n}$ values is 7 and Pitavastatin $0.013 \mu \mathrm{g} / \mathrm{ml}$ and $\mathrm{s} / \mathrm{n}$ value 3 . The $\mathrm{LOQ}$ concentration for Fenofibric acid $0.722 \mu \mathrm{g} / \mathrm{ml}$ and their s/n values are 28 and Pitavastatin $0.041 \mu \mathrm{g} / \mathrm{ml}$ and $\mathrm{s} / \mathrm{n}$ value is 23 . The method is validated as per the US FDA guidelines [30].

\section{Robustness}

The conditions of the experiment were designed to test the robustness of the established system intentionally altered, such as flow rate, mobile phase in organic percentage in all these varied conditions. Robustness results for Fenofibric acid and Pitavastatin found to be within the limit and results are tabulated in table 7 .

Table 7: Robustness data of fenofibric acid and pitavastatin

\begin{tabular}{lll}
\hline Parameter name & \% RSD & Pitavastatin \\
\cline { 2 - 3 } & Fenofibric acid & 0.88 \\
\hline Flow minus $(0.8 \mathrm{ml} / \mathrm{min}$ & 0.74 & 0.54 \\
Flow plus $(1.2 \mathrm{ml} / \mathrm{min})$ & 0.29 & 0.91 \\
Organic minus $(-10 \%)$ & 1.56 & 0.74 \\
Organic plus $(+10 \%)$ & 0.83 & \\
\hline
\end{tabular}

Table 8: Stability results of fenofibric acid and pitavastatin

\begin{tabular}{lllll}
\hline Stability & Fenofibric acid & & Pitavastatin \\
\cline { 2 - 5 } & Purity & \% of deviation & Purity & \% of deviation \\
\hline Initial & 99.99 & 0.01 & 99.99 & 0.01 \\
$6 \mathrm{H}$ & 99.75 & 0.22 & 99.61 & 0.37 \\
$12 \mathrm{H}$ & 99.56 & 0.47 & 99.42 & 0.49 \\
$18 \mathrm{H}$ & 99.31 & 0.63 & 99.27 & 0.74 \\
$24 \mathrm{H}$ & 99.11 & 0.84 & 98.97 & 0.97 \\
\hline
\end{tabular}

\section{Stability}

The standard and standard solution was kept at room temperature and at $2-8{ }^{\circ} \mathrm{C}$ up to $24 \mathrm{~h}$. Then these solutions were pumped into the device and calculate the $\%$ of deviation from initial to $24 \mathrm{~h}$ [31]. There was no significant deviation observed and confirmed that the solutions were stable up to $24 \mathrm{~h}$ percentage of the assay was not quite $2 \%$. There is no effect in storage conditions for Fenofibric acid and Pitavastatin drugs. The results are given below table 8 .

\section{Degradation studies}

The Pitavastatin and Fenofibric acid standard was subjected into various forced degradation conditions to effect partial degradation of the drug. Studies of forced degradation have been carried out to find out that the method is suitable for products of degradation [32,33]. In addition, the studies provide details about the conditions during which the drug is unstable, in order that the measures are often taken during formulation to avoid potential instabilities [34].

\section{Acid degradation}

Acid degradation was done by using $1 \mathrm{~N} \mathrm{HCl}$ and $15.42 \%$ of Fenofibric acid and $14.76 \%$ of Pitavastatin degradation was observed.

\section{Alkali degradation}

Alkali degradation was done at $1 \mathrm{~N} \mathrm{NaOH}$ and $14.96 \%$ of Fenofibric acid and $14.22 \%$ of Pitavastatin degradation was observed.

\section{Peroxide degradation}

Peroxide degradation was performed with $30 \%$ hydrogen peroxide and $13.25 \%$ Fenofibric acid, $13.96 \%$ of Pitavastatin degradation was observed.

\section{Reduction degradation}

Reduction degradation was performed with $30 \%$ sodium bi sulphate solution, $12.47 \%$ Fenofibric acid and $12.54 \%$ Pitavastatin degradation was observed.

\section{Thermal degradation}

In thermal degradation, the standard was degraded to $12.11 \%$ of Fenofibric acid and $11.37 \%$ of Pitavastatin.

\section{Degradation of hydrolysis}

In hydrolysis degradation, the standard was degraded to $11.63 \%$ of Fenofibric acid and $11.59 \%$ of Pitavastatin.

All degradation results are tabulated in table 9.

Table 9: Forced degradation results of fenofibric acid and pitavastatin

\begin{tabular}{llll}
\hline Degradation condition & Fenofibric acid & \multicolumn{2}{l}{ Pitavastatin } \\
\cline { 2 - 4 } & \% Assay & \% Deg & \% Assay \\
\hline Acid degradation & 84.58 & 15.42 & 85.24 \\
Alkali degradation & 85.04 & 14.96 & 85.78 \\
Peroxide degradation & 86.75 & 13.25 & 86.04 \\
Reduction degradation & 87.53 & 12.47 & 87.46 \\
Thermal degradation & 87.89 & 12.11 & 88.63 \\
Hydrolysis degradation & 88.37 & 11.63 & 13.92 \\
\hline
\end{tabular}

\section{CONCLUSION}

We present in this article simple, selective, validated and welldefined stability that shows gradient RP-HPLC methodology for the quantitative determination of Fenofibric acid and Pitavastatin. All the products of degradation formed during the stress conditions and the related active pharma ingredients are well separated and peaks were well resolved from each other and separate with an appropriate retention time, indicating that the proposed method to be fast, simple, feasible and affordable in assay condition.

Therefore the developed method during stability tests, it can be used for routine analysis of production standards and to verify the quality of drug standards during stability studies. 


\section{ACKNOWLEDGEMENT}

The authors are thankful to Shree Icon Pharmaceutical Laboratories to complete this research work.

\section{AUTHORS CONTRIBUTIONS}

All authors have contributed equally.

\section{CONFLICTS OF INTERESTS}

\section{Declared none}

\section{REFERENCES}

1. Fredrickson DS, Lees RS. A system for phenotyping hyperlipoproteinemia. Circulation 1965;31:321-7.

2. Wojcicki J, Pawlik A, Samochowiec L, Kaldo Ska M, Mysliwiec Z. Clinical evaluation of lecithin as a lipid-lowering agent. Phytother Res 1995;9:597-9.

3. Blair HA, Dhillon S. Omega-3 carboxylic acids (Epanova): a review of its use in patients with severe hypertriglyceridemia. Am J Cardiovasc Drugs 2014;14:393-400.

4. Berglund L, Brunzell JD, Goldberg AC. Evaluation and treatment of hypertriglyceridemia: an endocrine society clinical practice guideline. J Clin Endocrinol Metab 2012;97:2969-89.

5. Norata GD, Pirillo A, Ammirati E, Catapano AL. Emerging role of high-density lipoproteins as a player in the immune system. Atherosclerosis 2012;220:11-21.

6. Shah AS, Tan L, Long JL, Davidson WS. Proteomic diversity of high density lipoproteins: our emerging understanding of its importance in lipid transport and beyond. J Lipid Res 2013;54:2575-85.

7. Gill Jason, Sara Herd, Natassa Tsetsonis, Adrianne Hardman. Are the reductions in triacylglycerol and insulin levels after exercise related? Clin Sci 2002;102:223-31.

8. Zhang J, Herscovitz H. Nascent lipidated apolipoprotein B is transported to the golgi as an incompletely folded intermediate as probed by its association with network of endoplasmic reticulum molecular chaperones, GRP94, ERp72, BiP, calreticulin, and cyclophilin B. J Biol Chem 2003;278:7459-68.

9. Peterson MM, Mack JL, Hall PR, Alsup AA, Alexander SM, Sully EK, et al. Apolipoprotein B is an innate barrier against invasive staphylococcus aureus infection. Cell Host Microbe 2008:4:507-9.

10. Gremel, Gabriela, Wanders, Alkwin, Cedernaes, Jonathan, et al. The human gastrointestinal tract-specific transcriptome and proteome as defined by RNA sequencing and antibody-based profiling. J Gastroenterol 2015;50:46-57.

11. Lappin, Graham, Rowland, Malcolm, Garner R. The use of isotopes in the determination of absolute bioavailability of drugs in humans. Expert Opinion Drug Metab Toxicol 2006;2:419-27.

12. Alenghat FJ, Davis AM. Management of blood cholesterol. JAMA 2019;321:800-1.

13. Kajinami K, Takekoshi N, Saito Y. Pitavastatin: efficacy and safety profiles of a novel synthetic HMG-CoA reductase inhibitor. Cardiovasc Drug Rev 2003;21:199-215.

14. Bellosta S, Corsini A. Statin drug interactions and related adverse reactions. Expert Opin Drug Saf 2012;11:933-46.

15. Menzies SA, Volkmar N, Van den Boomen DJ, Timms RT, Dickson AS, Nathan JA, et al. The sterol-responsive RNF145 E3 ubiquitin ligase mediates the degradation of HMG-CoA reductase together with gp78 and Hrd1 (PDF). eLife 2018;7:e40009.

16. Akioyamen LE, Genest J, Shan SD, Reel RL, Albaum JM, Chu A, et al. Estimating the prevalence of heterozygous familial hypercholesterolemia: a systematic review and metaanalysis. Br Med J Open 2017;7:e016461.

17. Van Craeyveld E, Jacobs F, Gordts SC, De Geest B. Gene therapy for familial hypercholesterolemia.Curr Pharm Des 2011; $17: 2575-91$.
18. Hooper L, Martin N, Jimoh OF, Kirk C, Foster E, Abdelhamid AS. Reduction in saturated fat intake for cardiovascular disease. Cochrane Database Sys Rev 2020;5:CD011737.

19. Sacks FM, Lichtenstein AH, Wu JH, Appel LJ, Creager MA, Kris Etherton PM, et al. Dietary fats and cardiovascular disease: a presidential advisory from the american heart association. Circulation 2017;136:e1-23.

20. Garrison SR, Dormuth CR, Morrow RL, Carney GA, Khan KM. Nocturnal leg cramps and prescription use that precedes them: a sequence symmetry analysis. Arch Intern Med 2012;172:120-6.

21. Qu H, Guo M, Chai H, Wang WT, Gao ZY, Shi DZ. effects of coenzyme q10 on statin-induced myopathy: an updated metaanalysis of randomized controlled trials. J Am Heart Assoc 2018;7:e009835

22. Mukhtar RY, Reid J, Reckless JP. Pitavastatin. Int J Clin Practice 2005;59:239-52.

23. Kawashiri MA, Nohara A, Tada H, Mori M, Tsuchida M, Katsuda $\mathrm{S}$, et al. Comparison of effects of pitavastatin and atorvastatin on plasma coenzyme Q10 in heterozygous familial hypercholesterolemia: results from a crossover study. Clin Pharmacol Ther 2008;83:731-9.

24. Caprio, Sonia, Pierpont, Bridget, Kursawe, Romy. The adipose tissue expandability hypothesis: a potential mechanism for insulin resistance in obese youth. Horm Mol Biol Clin Investig 2018;33. DOI:10.1515/hmbci-2018-0005

25. Nakagomi A, Shibui T, Kohashi K, Kosugi M, Kusama Y, Atarashi $\mathrm{H}$, et al. Differential effects of atorvastatin and pitavastatin on inflammation, insulin resistance, and the carotid intima-media thickness in patients with dyslipidemia. J Atheroscler Thromb 2015;22:1158-71.

26. Villegas R, Xiang YB, Elasy T, Xu WH, Cai H, Cai Q, et al. purinerich foods, protein intake, and the prevalence of hyperuricemia: the shanghai men's health study. Nutr Metab Cardiovascular Diseases 2011;22:409-16.

27. Ogata N, Fujimori S, Oka Y, Kaneko K. Effects of three strong statins (atorvastatin, pitavastatin, and rosuvastatin) on serum uric acid levels in dyslipidemic patients. Nucleosides Nucleotides Nucleic Acids 2011;29:321-4.

28. Shivani CP, Maheshwari DG. Development and validation of UV spectrometric and HPLC method for estimation of escitalopram oxalate and flupentixol dihydrochloride in combined dosage form. AJPTI 2016;4:59-70.

29. Supriya T, Naresh D, Vijaya Kumar G, Haneer MA. Stability indicating RP-HPLC method development and validation for simultaneous estimation of escitalopram and flupentixol pure and marketed formulation. Asian J Pharm Res 2018;8:4-10.

30. Swati K, Abhishek P, Sushank S, Bothiraja C, Atmaram P. Highperformance liquid chromatography for the simultaneous estimation of cefoperazone and sulbactam in rat plasma and its importance in therapeutic drug monitoring. Int J Pharm Pharm Sci 2020;12:92-7.

31. Vijayakumari M, Balasekhar Reddy Ch. Stability indicating validated HPLC method for the determination of zanubrutinib in the bulk and pharmaceutical dosage form. Asian J Pharm Clin Res 2020;13:159-62.

32. Rajakumari R, Sreenivasa Rao S. Stress degradation studies and development of a validated RP-HPLC method for determination of tiagabine in the presence of its degradation products. Int J Pharm Pharm Sci 2016;8:230-6.

33. Charu Pandya P, Sadhana Rajput J. Development and validation of stability-indicating method RP-HPLC method of Acotiamide. Int J Pharm Pharm Sci 2018;10:1-8.

34. Birva Athavia A, Zarna Dedania R. Stability indicating HPLC method for determination of vilazodone hydrochloride. Int J Curr Pharm Res 2017;9:123-9. 